\title{
Musica, Afeto, Psicanalise ${ }^{1}$
}

David Bernard²

\section{RESUMO}

A questão se encaminha sobre por que, e em que, a música pode afetar os seres falantes. Marcel Proust, em sua Busca, respondeu a isto da sua própria maneira. Igualmente tomaremos como apoio o que ele nos ensina para questionar o que a psicanálise, por sua vez, poderia dizer a este respeito. Por fim, gostaríamos, assim, de precisar as relações entre a música e a linguagem e as repercussões destas na clínica.

PalavRAs-Chave: Música, afeto, amor, linguagem, lalangue.

\footnotetext{
1 Artigo originalmente publicado em: Bernard D. "Musique, affect, psychanalyse », Champ lacanien, 2012/2 (No 12), p. 131-140. Disponível em: https://www.cairn.info/revue-champ-lacanien-2012-2-page131.htm. Tradução de Renata Mattos Avril.

2 Professor e pesquisador em psicopatologia pela Université de Rennes (França). Psicanalista à Rennes e membro da École de Psychanalyse des Forums du Champ Lacanien. Autor de "Lacan et la honte" (Éditions du Champ Lacanien, 2020, em reedição) e organizador da obra coletiva "Lacan avec Wedekind" (Éditions Presses Universitaires de Rennes). Endereço postal: 20 rue des Fossés 35000 Rennes France. E-mail: dabernard2@yahoo.fr
} 
Vou me debruçar aqui, sobre o que a música ensina à psicanálise, sobre nossa relação à linguagem e ao afeto. Sobre este ponto, como, de saída, não nos espantar diante do pouco caso que a psicanálise parece fazer quanto à música? Isso significa que continuaremos aqui a nos contaminar do silêncio de Freud sobre a música? Mas do que se tratava este silêncio? Em seu texto "O Moisés de Michelangelo", Freud nos indica. Freud não era simplesmente indiferente à música, ele recusava ser afetado pela música em razão deste afeto Ihe ser enigmático e recusar interpretação. "Uma disposição (...) revolta-se em mim, recusando que eu possa ser comovido sem ao mesmo tempo saber porque sou assim tomado e o que me toma" (FREUD, 1985, p. 87).

A música, e seu poder de afeto, foram portanto enigma a Freud e resistem à teorização. A clínica cotidiana basta para demonstrar como ela acompanha, ritmiza e faz a história de cada um. O que o cinema, por sua vez, sabe e nos lembra desde sua origem, dando a cada uma de suas histórias contadas a sua música. Entretanto, mais do que deduzir deste silêncio da psicanálise uma simples resistência de seus praticantes, eu verei sobretudo o índice de que, com efeito, faltava à teoria freudiana um conceito. Esta é a minha hipótese: somente os conceitos, forjados tardiamente por Lacan, de lalangue e de parlêtre ${ }^{3}$ permitem aproximar um pouco isso que nos diz a música e seus efeitos de afetos enigmáticos.

Tenho como proposta, esclarecer o conceito de lalangue, bastante complicado de um ponto de vista teórico, mas, o que creio ser signo de sua pertinência, muito simples de ilustrar clinicamente. Todavia, antes de aí chegar, tomarei como ponto de partida uma simples questão: a música, é um fato, nos afeta. Apenas saberíamos, para tanto, nós que somos por ela tocados, tomados, dizia Freud, do que ela nos fala? E mesmo, podemos sabê-lo? Questões que poderíamos reduzir àquela que atravessa séculos: "Sonata, que queres?". É esta que, a seu modo, Proust, grande conhecedor da linguagem, coloca em "Em busca do tempo perdido". Uma frase musical, extraída de uma Sonata para piano e violino de Vinteuil, reaparece bastante no texto, tal qual um ritornelo, para marcar os tempos do amor entre Swann e Odette. Ainda que seja desta frase musical que Swann se apaixona primeiramente. A frase musical foi uma

\footnotetext{
${ }^{3}$ Nota de tradução: Apesar de haver traduções para os neologismos em francês cunhados por Lacan, lalangue e parlêtre, respectivamente alíngua ou lalíngua e falasser, optamos aqui por utilizar os termos originais.
} 
das condições do amor deles. Foi preciso, antes, que um pianista a toque para que, então, em uma noite, Swann considere Odette "deliciosa" (PROUST, 1992a, p. 205) pela primeira vez e a olhe de outra forma. Em seguida, foi Odette que, consentindo Ihe tocar repetidas vezes a sonata ao piano, portou sobre ela a frase musical, tal qual uma joia presenteada grampeada em seu corpete (Ibid., p. 211). E isso, não sem colocar suas condições, exigindo de Swann que ele se recuse, a partir deste momento, a pedir a outros que não ela que lhe toquem esta sonata. "Por que você precisaria do resto?, ela Ihe disse. É isso, nossa música" (Ibid.). Enfim, é ainda ao escutá-la que, depois de ter sido atravessado pelos tormentos do ciúme, Swann poderá se separar de Odette, para se dirigir por um tempo em direção de outros.

Mas deixemos aqui por um instante a verdade mentirosa desta história para isolar, sobretudo, o que Proust diz sobre o encontro, para Swann, com esta pequena frase. No momento em que ele escutava pela primeira vez a Sonata de Vinteuil, eis que ele foi escutado, "sem poder dar um nome ao que lhe agradava, subitamente encantado". A frase o tinha afetado de uma "dessas impressões que são, talvez, as únicas puramente musicais, inextensas, inteiramente originais, irredutíveis a qualquer outra ordem de impressões" (Ibid., p. 202). A frase, leremos ainda, "propôs-lhe rapidamente volúpias particulares, das quais ele nunca tinha tido ideia antes de ouvila, as quais ele sentia que nada além dela poderia the fazer conhecer, e ele experimentou através dela um amor desconhecido" (Ibid., p. 203). "Este amor" (Ibid.) que afeta Swann lhe é, com efeito, enigmático. E é por esta razão, escreve Proust, que na escuta desta frase "uma margem (...) estava reservada a um gozo que (...) não correspondia a nenhum objeto exterior" (Ibid. p. 227). "De modo que essas partes da alma de Swann onde a pequena frase tinha apagado a preocupação dos interesses materiais (...), ela as teria deixado vacantes e em branco, e ele estava livre para inscrever nela o nome de Odette" (Ibid., p. 228).

Assim, Swann, ao escutar esta frase musical, experimenta um gozo sobre o qual ele tem dificuldade a dizer qual é. Ele sabe igualmente que a frase the fala (Ibid., p. 203), mas ignora o que ela lhe diz. A frase apenas passa, simples batimento sonoro de uma presença-ausência de aspecto feminino. Desde então, ela lhe faz signo, mas de quê? Em sua própria modulação, de um amor frágil. "A pequena frase aparecia, dançante, pastoral, intercalada, episódica, pertencendo a um outro mundo. Ela 
passava $^{4}(\ldots)$, distribuindo aqui e ali os dons de sua graça, com o mesmo inefável sorriso; mas Swann acreditava distingui-la agora do desencantamento. Ela parecia conhecer a vaidade dessa felicidade sobre a qual ela mostrava a voz" (Ibid., p. 211).

\begin{abstract}
Ele começava a se dar conta de tudo o que havia nela de doloroso, talvez mesmo de secretamente desapaziguado no fundo da doçura desta frase, mas ele não podia sofrer. Que importa que ela lhe diga que o amor é frágil, o seu era tão forte! (...) Ele fazia Odette tocá-la novamente dez vezes, vinte vezes, exigindo ao mesmo tempo que ela não cessasse de beijá-lo" (Ibid., p. 228).
\end{abstract}

É, portanto, sob o fundo de seu amor pela frase que Swann se contará um outro amor, unindo-o à Odette. É sob o fundo desses brancos que ele escreverá o nome de Odette e inventará a história deles, seu início, assim como seu fim, momentâneo.

Um ano mais tarde, no momento em que Swann esperava tê-lo esquecido, é, com efeito, a Sonata que vem novamente surpreendê-lo, carregando com ela, em um instante, toda a memória do amor deles: "todas essas lembranças do tempo em que Odette estava dele enamorada, e que ele tinha conseguido, até este dia, manter invisíveis nas profundezas de seu ser (...) tinham tornado a subir para lhe cantar perdidamente (...) os refrões esquecidos da felicidade" (Ibid., p. 326). De onde já poderíamos deduzir que: somente os refrões não esquecem nada. A música é a memória ${ }^{5}$. Todavia, precisemos mais, ainda. A frase traz novamente, por certo, à sua memória as lembranças do amor deles e as falsas promessas que ele continha. Mas isso sem the dizer o porquê. Posto que é, com efeito, em seu peso de enigma que a frase surge novamente. Ela se faz a ele lembrar como puro dizer, enigmática. A frase é "no ar, como um ser sobrenatural e puro que passa desenrolando sua mensagem invisível" (Ibid., p. 202). "Como se os instrumentistas tocassem bem menos a pequena frase do que os ritos exigidos por ela para que ela pudesse aparecer" (Ibid.). Razão pela qual caberá ao próprio Swann decidir sobre o seu sentido, novo. A frase, hoje, Ihe cantará a separação possível deles. Ela pareceria "Ihe dizer como outrora de sua felicidade: 'O que é isso? Tudo isso não é nada'. Enquanto que, naquele tempo, ele adivinharia o sofrimento em seu sorriso, em sua entonação límpida e desencantada, hoje ele encontraria nela sobretudo a graça de uma resignação quase alegre" (Ibid., p. 329).

\footnotetext{
${ }^{4}$ Grifos do autor.

5 "O canto é ele mesmo memória", dirá por sua vez Maurice Blanchot (1969, p. 459).
} 
Assim, nestas páginas, o que nos diz Proust sobre a música? De um lado, sua dimensão de significância ${ }^{6}$. A frase musical se reduz aqui ao que Agambem (1997, p. 70) dizia sobre a voz na enunciação: um "puro querer-dizer" ${ }^{7}$. A frase passa, apenas evocando em meias-palavras a Swann o que ele the teria a dizer, meias-palavras suficientes, no entanto, para lhe dar corpo, feminino, desejável mais fugidio. "E enquanto ela passava, leve, (...), Ihe dizia o que tinha a lhe dizer e ele escrutava todas as palavras, lamentando vê-las voar para longe tão rapidamente, fazendo involuntariamente com seus lábios um movimento de beijar, na passagem, o corpo harmonioso e fugidio (PROUST, 1992, p. 329)". Nesses momentos, no entanto, Swann se sentia menos sozinho. Eis aqui uma outra dimensão da música que Proust sublinha: um apaziguamento, seja ele momentâneo, do sentimento de exílio (Ibid.). A frase é, para Swann uma confidência (Ibid., 328), à qual ele pode confiar sua solidão e sua tristeza. É dizer igualmente se a música o afeta. De uma forma enigmática, por certo, já que as palavras não conseguem dizer o que ela revela nele. Mas contudo, de modo garantido, verdadeiro toque do real. Perceber o que ele denomina "as coisas da música" seria imaginar não mais "um teclado mesquinho de sete notas, mas um teclado incomensurável, quase ainda totalmente desconhecido, onde somente aqui e ele, (estariam) separadas (...) algumas das milhões de teclas de ternura, de paixão, de coragem, de serenidade, que o compõem" (Ibid., 330).

Além disso, a essas dimensões de significância e de afeto, Proust acrescenta a da repetição. A frase musical, no romance como na Sonata, tem uma estrutura de um ritornelo, deixando Swann sempre "à espera" (Ibid., p. 326) de seu retorno. Ao ponto que a dita frase parece gravada na alma de Swann. "Mesmo quando ele não pensava na pequena frase, ela existia latente em seu espírito" (Ibid., p. 331). Doravante, Swann não poderá fazer de outro modo senão viver com. "Desse modo, a frase de Vinteuil (...) havia se casado com (sua) condição mortal, tomado alguma coisa de humano que era bastante tocante" (Ibid.).

Há, portanto, amores. Há o que leva Swann à pequena frase, como há aquele que, a partir daí, ele elevará: seu amor por Odette. Sublinhamos, então, que o

\footnotetext{
${ }^{6}$ No sentido que Lacan a compreende em Le Séminaire, Livre XX, Encore, Seuil, Paris, 1975, p. 23. O termo de significância não designa, portanto, uma significação preciso, mas sobretudo a possibilidade de todos os sentidos possíveis.

${ }^{7}$ A notar que, segundo Georges Groddeck (1972, p. 3), a palavra música vem do grego e deriva da palavra "musa", "mas que musa estava na origem de montia e significava 'que faz sentido', 'que quer dizer"'.
} 
primeiro, diz Proust, é um amor sem objeto, ao menos denominado. Nada o porta senão seu efeito de afeto para Swann e sua significância enigmática. Contudo, esta significância, suscitada pela modulação sonora da frase, não seria justamente aquilo que afeta? A filósofa, musicóloga e poeta Danielle Cohen-Levinas, em diversos e notáveis artigos consagrados à música e aos afetos, o deixa, à sua maneira, supor. "A música, ela escreve, diz coisas sobre as palavras que as palavras não desconfiam. Elas o dizem na retirada da palavra" (COHEN-LEVINAS, 1998a, p. 7). Em outro lugar, ela continua: "A identidade da obra musical (...) é a manifestação de uma essência ou de um efeito de língua que diz mais sobre ela que a própria língua. Seguir narrativamente a música é aceitar nunca alcançar a história que ela nos conta" (COHEN-LEVINAS, 1998b, p. 36). Sublinho aqui a tese da autora: a música é um efeito de língua que toca o que são as palavras, sem se reduzir a uma significação. Ao ponto que, dirá um outro filósofo e poeta, Michel Deguy (1998, p. 19): "Precisamente porque ela não é linguageira (não é significante), uma peça musical que eu conheço me surpreende a cada vez de novo... Por eu não conhecê-la como texto, ela pode me dizer alguma coisa outra a cada acordo". Da música, o ser falante não poderia, portanto, se cansar.

A música não pode cansar, mas, ao contrário, re-gozijar ${ }^{8}$, na medida exata em que ela não é linguagem. Ela é um efeito de língua, nunca reabsorvida numa significação. Assim como a poesia, ela se separa do sentido, podendo, a partir daí, abrir a todos os sentidos. Concluo disso: a música é epifânica. Lalangue é a sua verdadeira Musa. Assim como lalangue é de essência musical, a música é um efeito de lalangue, não da linguagem. No sentido que Lacan entendia lalangue, a saber, uma sucessão de unidades significantes fora do sentido que se distinguem pela sua materialidade sonora e que constituem a apreensão primeira da língua materna quando a criança ainda bem nova ainda não acede ao registro do sentido. O próprio Dante, demonstra Roger Dragonetti (2006, p. 84), teve a intuição disso, para quem, ele escreve, "a ideia da música está intimamente associada ao que faz parte da essência mesma de uma língua materna". Razão pela qual somente o conceito de

\footnotetext{
${ }^{8}$ Nota de tradução: No original, "re-jouir", que pela escansão proposta pelo autor nesta palavra, faz nela destacar sua dimensão de gozo, de um "gozar"(jouir).
} 
lalangue me parece esclarecer, sem nunca interpretá-los, os afetos que a música suscita nos parlêtres.

Nisso ainda, o amor da música poderia se reunir a este amor de lalangue, que deu título a uma obra, por sinal um pouco seca, de Jean-Claude Milner. E é por essa razão que há na música, assim como no canto e na poesia, um saber fazer aí com a "potência musical" (LACAN, 1966, p. 533) do significante, o qual não é sem benefício. Giorgio Agamben o notou a seu modo. No canto como na poesia, alguma coisa se encontra, que tem traço no evento da linguagem (ele não diz lalangue) e que nutre o afeto de amor (AGAMBEN, 1997, p. 122). A poesia e o canto, da mesma forma que a música, são uma experiência amorosa da linguagem. O evento musical do verso, dirá ele, não sem evocar a experiência de Proust, é "o lugar de uma memória e de uma repetição" (Ibid., p. 139). "Através do elemento musical, a palavra poética comemora (...) seu próprio inacessível lugar originário e exprime o caráter indizível do evento de linguagem (ele encontra, dito de outra forma, o inencontrável)" (Ibid.).

A psicanálise permite, então, me parece, precisar o que a música encontra, de inencontrável. Lembro sobre este ponto uma curta, mas capital, observação de Lacan quanto às crianças e o gosto insaciável destas pela significância. Não é somente as crianças pequenas, dizia ele depois de Freud, que gostam que thes contemos sempre a mesma história, fazendo atenção a que o adulto, um pouco cansado, não mude nenhuma palavra. Um modo de, notemos, reduzir o texto a um simples ritornelo. Fazendo isso, o que é que a criança deseja, em vão? Não menos, responde Lacan (1973, p. 60), que atingir à "primazia da significância enquanto tal". Em vão, o demonstrou Marc Strauss (Inédito, p. 78), uma vez que a criança não pode encontrar, assim, a representação, a significação, da perda do objeto que lhe teria causado sua entrada na linguagem. Eis aqui, portanto, quanto ao inencontrável. Mas, por essa razão, continua Marc Strauss, nesta sede de significância, um outro gozo se encontra. Trata-se aqui do gozo de lalangue, fora-do-sentido, a qual se satisfaz nos ritornelos significantes. O sucesso desses outros ritornelos que são as cantigas, e que alegrarão desde muito cedo a criança, verificam isso. Brincando com o significante reduzindo assim à sua potência musical, a criança nos mostra que é "musicalmente" que ela

\footnotetext{
${ }^{9}$ Muitos outros, de disciplinas diferentes, se reúnem quanto a este ponto. Cf., por exemplo: François Perrier (1972, p. 95), Philippe Lacoue-Labarthe (2005, p. 25-27), Marina Yaguello (1981, p. 30) e Clément Rosset (1979, p. 83-87).
} 
fará sua entrada na linguagem. Que se trate aqui da musicalidade sonora dos significantes do Outro, dos primeiros jogos cantarolados da criança, ou ainda do canto no qual ela começará a advir em seu primeiro endereçamento ao Outro.

Tomarei dois exemplos para demonstrar esse ponto. Quanto ao primeiro, tratase de uma anedota trazida por François Perrier (1972) em uma revista consagrada, justamente, às relações entre música e psicanálise. Uma mãe se entedia em Maloles-Bains, numa quinta-feira do mês de agosto, sem marido ou amante presentes, mas com seu filho nos braços. Quando, de repente, passa uma velha pescadora. "Camarões, madame", ela lança. De fato, a mamãe ainda não escuta, posto que a velha mulher lança sua frase como se não se dirigisse a um interlocutor preciso, de forma mecânica. Mas ela o faz de forma melodiosa, tal qual um ritornelo. Eis aí que a criança, por sua vez, acusa a recepção do pequeno ritornelo e que, cantarolando, retoma a simples melodia. Abre-se então, surpresa, a orelha materna. Aquilo que ela não podia escutar do canto da velha pescadora, perdida que estava em seu tédio, este desejo de Outra coisa, Ihe chega, assim, através de seu pequeno filho. O bebê será músico, se diz ela. E eis ela que, tocada pelo canto do seu filho, se coloca então a imitá-lo, a retomar em bocca chiusa a melodia do ritornelo, ao qual a criança responderá imitando-a etc... Assim, de eco em eco, eis aqui que os dois, na intimidade de seu corpo a corpo, deixam aí advir lalangue, brincando com sua musicalidade. E não se sabe quem, mãe ou criança, se encontrará aqui mais afetado por isso.

O segundo exemplo é mais conhecido, posto que se trata do Fort- $D a^{10}$. Somente, não teríamos visto, assim como Deleuze e Guattari (1980, p. 368), que o Fort-Da é igualmente um primeiro canto, um ritornelo? "Encantamento", diria Lacan, termo cuja etimologia deriva do termo cantare, o qual significa cantar. "É com seu objeto (objeto a perdido em sua entrada na linguagem) que a criança salta as fronteiras do sua propriedade, transformada em poços, e que ela começa o encantamento" (LACAN, 1973, p. 60). Ao corpo falante, seria preciso, então, acrescentar o corpo cantante, assim como o corpo dançante, o corpo brincado ${ }^{11}$, cada um deles se animam em torno deste objeto que Ihes faz falta. Georges Didi-Huberman

\footnotetext{
${ }^{10}$ Lembro que se trata aqui do jogo que o neto de Freud, enquanto era ainda bem pequeno, inventou para responder à ausência de sua mãe. Ele fazia, então, aparecer e desaparecer por baixo de seu berço uma bobina, que continha um fio, enquanto repetia alternadamente: Fort e $\mathrm{Da}$.

${ }^{11}$ Cf., sobre esse ponto, a nota de rodapé em que Freud (1981, p. P. 53) nos indica que seu neto também se divertiu diante do espelho.
} 
(2006, p. 169), de quem tomo esta fórmula, concluiria a este respeito, sobre a dança: "o dançarino dança somente para se separar". Não poderíamos dizer a mesma coisa sobre aquele que declama, do músico, do cantor, e outras guisas do parlêtre? É o que, lá ainda, as crianças, brincando com a estrutura, dão a ver e a ouvir desde muito cedo. Quando, no momento de suas primeiras tomadas de palavra, de sua separação para com o Outro, este último se surpreenderá ao vê-las avançar concomitantemente a suas primeiras danças, assim como que a seus primeiros cantos e seus primeiros jogos cênicos de se fantasiar. Proust (1992b, p. 429), que sabia se surpreender, o dirá de um belo modo: a infância mistura todas as artes.

Enfim, não existiria também no "desejo de música" (DUSAPIN, 2007, p. 37) que anima os parlêtres a marca do significante, não em seu valor de sentido, mas em sua potência musical? Em outros termos, a sobrevivência ${ }^{12}$ deste desejo da criança, de poder gozar da primazia da significância. Ao que eu acrescentaria que, se a música consoa com lalangue, seria possível, então, que os efeitos que ela produz, nunca sensatos, esclareçam esses efeitos de afetos enigmáticos que, dizia Lacan (1975, p. 127), lalangue suscita. Menos estes de um sujeito do que os de um parlêtre. Razão, talvez, pela qual, segundo Alain Badiou ${ }^{13}$, a música trata apenas de duas paixões, a tristeza e a alegria. Ou seja, as mesmas que suscitam a entrada na linguagem, via lalangue. Tendo como efeito destes afetos enigmáticos que o sujeito nunca será capaz de dizer o que, precisamente, em sua entrada na linguagem ele terá perdido e achado ao ritmo desta ausência-presença do Fort-Da. Nisso, seria possível que a música, como lugar de memória, faça sempre re-tocar nossa origem êxtima, aquela, como dizia Lacan, da qual o parlêtre se encontra para sempre excluído (LACAN, 1976, p. 8). O que nos leva novamente a Proust (1992a, p. 331): "A frase de Vinteuil (...) havia se casado com (sua) condição mortal, tomado alguma coisa de humano que era bastante tocante". E igualmente a Lacan, além de Deleuze. Lalangue é um ritornelo, diria $u^{14}{ }^{14}$, enquanto que o outro diria alhures: "O ritornelo é o conteúdo da música" (DELEUZE e GUATTARI, 1980, p. 368).

\footnotetext{
12 Cf., sobre esse ponto, Dominique Avron (1972, p. 105).

13 Trazido por François Regnault em "Psychanalyse et musique", disponível na internet.

${ }^{14} \mathrm{Na}$ lição de 08 de janeiro de 1974 do Seminário Les Non-dupes errent de Jacques Lacan (Inédito a).
} 
Concluirei sublinhando que Lacan nos oferece diversas outras indicações sobre as afinidades entre lalangue e, senão a música, ao menos o canto ${ }^{15}$. Assim o é o neologismo lalangue, oriundo de lalação, que deriva do termo latim lalare, o qual designava as canções cantaroladas às crianças para adormece-las. Porém, mais além, é também a Joyce que deveríamos nos conduzir. Sabemos, com efeito, o que Lacan deve a seu Finnegans Wake, de sua teorização sobre lalangue, menos o que o escritor demonstra sobre seus laços para com a música. Assim, pensemos a esse pequeno ritornelo inventado por Lacan para exemplificar o que é lalangue: "L'on l'a, l'on l'a de l'air, l'on l'aire, de l'on l'a16". Ao que ele acrescenta: "Isso se canta, ocasionalmente, e Joyce não se priva de fazê-lo" (LACAN, 1987, p. 35). Joyce, justamente, além do seu amor pelo canto, via nos jogos de palavras de seu capítulo no livro de Ulisses intitulado "As Sereias", que anunciava os jogos de Finnegans Wake, aquilo que ele denominava efeitos musicais. A propósito destes, ele perguntará, aliás, um dia a seu amigo Weiss: "Você não acha os efeitos musicais de minhas "Sereias" melhores do que os de Wagner?"17.

\footnotetext{
${ }^{15}$ Cf., como outro exemplo, o poema que François Cheng cantarola a Lacan (Inédito b), na lição de 19 de abril de 1977 do Seminário L'insu que sait de l'une-bévue s'aile a mourre.

${ }^{16}$ Nota de tradução: Frase intraduzível para o português que propõe um jogo fonético e musical, por homofonias, tal qual uma lalação, colocando em ato o que está em jogo na sonoridade própria de lalangue. Algo que, de forma aproximativa, poderíamos ouvir como "UOM há, UOM há do ar, UOM aira, do UOM há". Evocando igualmente o que se tem, "l'on l'a" (temos isso), e o que parece se ter, o que se tem o ar de ter, "I'on l'a de l'air", e que nos faz tomar ar, airar "I'on l'aire". Acrescentamos que UOM faz referência homofônica ao francês, l'on, que evoca l'homme, o homem. Fazendo com que a frase lalada possa ser ouvida, finalmente, como: "o homem tem, o homem o tem do ar, o homem aira, do homem o tem".

17 Trazido por Daniel Ferrer (1995, p. 1453).
} 


\section{REFERÊNCIAS}

AGAMBEM, G. Le langage et la mort, Christian Bourgois, 1997.

AVRON, D. "Vers une métapsychologie de la musique", in Musique en jeu n9 . Paris : Seuil, 1972.

BLANCHOT, M. L’entretien infini, Gallimard, Paris, 1969.

COHEN-LEVINAS, D. “Le temps de la narrativité musicale”. In Rue Descartes n²1, PUF, Paris, 1998a.

COHEN-LEVINAS, D. “Prélude”. In Rue Descartes n²1, PUF, Paris, 1998 b.

DEGUY, M. “De la musique avant toute chose” In Rue Descartes n²1, PUF, Paris, 1998.

DELEUZE, G. et GUATTARI, F. Mille plateaux. Editions de Minuit, Paris, 1980.

DIDI-HUBERMAN, G. Le danseur des solitudes. Editions de Minuit, 2006.

DUSAPIN, P. Composer. Musique, Paradoxe, Flux. Fayard / Collège de France, Paris, 2007.

DRAGONETTI, R. Dante, la langue et le poème, Belin, Genève, 2006.

FERRER, D. “XI Les Sirènes, Notice », in Joyce J., Euvres T.II, La pléiade, Paris, 1995.

FREUD, S. “Au-delà du principe de plaisir”, in Essais de psychanalyse, Petite Bibliothèque Payot, 1981.

FREUD, S. "Le Moïse de Michel-Ange", in L'inquiétante étrangeté et autres essais, Paris : Folio-Essais, 1985.

GRODDECK, G. “Musique et inconscient”, in Musique en jeu n9, Seuil, Paris, 1972.

LACAN, J. "D'une question préliminaire à tout traitement possible de la psychose. In Ecrits. Paris : Seuil, 1966.

LACAN, J.“Joyce le symptôme II”, in Joyce avec Lacan. Paris :Navarin, 1987.

LACAN, J. Le Séminaire Livre XI, Les quatre concepts fondamentaux de la psychanalyse. Paris : Seuil,1973.

LACAN, J. Le Séminaire Livre XX, Encore. Paris : Seuil, 1975.

LACAN, J. Le Séminaire Livre XXI, Les non-dupes errent. Inédito a.

LACAN, J. Le Séminaire Livre XXIII, Le Sinthome. Paris : Seuil, 2005. 
LACAN, J.“Réponse à Marcel Ritter”. In Lettres de l'Ecole freudienne n¹8, Avril 1976.

LACAN, J. Le Séminaire Livre XXIV, L’insu que sait de l'une-bévue s'aile a mourre, Inédito $b$.

LACOUE-LABARTHE, P. Le chant des muses. Paris : Bayard, 2005.

PERRIER, F. “La musique déjouée”. In Musique en jeu n9. Paris : Seuil, 1972.

PROUST, M. "Du côté de chez Swann", T.I de A la recherché du temps perdu, Gallimard, Paris, 1992a.

PROUST, M. “A l'ombre des jeunes filles en fleurs”, T.II de A la recherche du temps perdu, Gallimard, Paris, $1992 b$.

ROSSET, C. L’objet singulier, Editions de Minuit, Paris, 1979.

STRAUSS, M. "Que veut-il ? Encore", Cours au Collège clinique de Paris des Formations Cliniques du Champ Lacanien. Inédit.

YAGUELLO, M. Alice au pays du langage. Paris : Seuil, 1981. 


\section{Music, AfFeCt, PsychoANALYSIS}

\section{ABSTRACT}

The question is about why, and how, music can affect the speaking beings. Marcel Proust, in his Research, has answered it in his own way. We will also take as support what he teaches us in order to question what psychoanalysis, in turn, could say about this. At the end, we would like thus to clarify the relations between music and language, as well as its repercussions in the clinic.

KEYWORDS: Music. Affect. Love. Language. Lalangue 


\section{Musique, Affect, Psychanalyse}

\section{RÉSUMÉ}

La question porte sur pourquoi, et en quoi, la musique peut affecter les êtres parlants. Marcel Proust, dans sa Recherche, y répondit à sa façon. Aussi prendrons-nous appui sur ce qu'il nous enseigne pour questionner ce que la psychanalyse, à son tour, pourrait en dire. Au terme, nous voudrions ainsi préciser les rapports de la musique et du langage, et leurs répercussions dans la clinique.

MotS-CLÉs: Musique. Affect. Amour. Langage. Lalangue 
RECEBIDO EM 26/09/2020

ApRovado EM 10/10/2020

(c) 2020 Psicanálise \& Barroco em revista

http://www.seer.unirio.br/index.php/psicanalise-barroco/index

revista@psicanaliseebarroco.pro.br

Programa de Pós-Graduação em Memória Social — UNIRIO

Memória, Subjetividade e Criação

www.memoriasocial.pro.br/proposta-area.php 